\title{
ANALISIS DAN IMPLEMENTASI E-COMMERCE MENGGUNAKAN CMS WORDPRESS PADA QUEENITA CLASSIC
}

\author{
Ekie Revsie Akbar ${ }^{1}$, Hendri Irawan ${ }^{2}$ \\ ${ }^{12}$ Fakultas Teknologi Informasi, Sistem Informasi, Universitas Budi Luhur, Jakarta, Indonesia \\ Email: ${ }^{1}$ ekierevsie@gmail.com, ${ }^{2}$ hendri.irawan@budiluhur.ac.id
}

\begin{abstract}
Abstrak - Queenita Classic adalah toko sparepart motor klasik yang terbentuk sejak tahun 2013 yang menyediakan berbagai produk seperti tangki, reflektor lampu, lampu sein, shockbaker, spedometer, dan masih banyak yang lainnya. Tidak hanya menjual sparepart saja, perusahaan ini juga menyediakan jasa untuk pemasangan sparepart. Hal ini tentu menjadi nilai lebih Queenita Classic dalam memberikan layanan kepada pelanggan. Dalam menjalankan usahanya Queenita Classic selalu mengalami permasalah yang terjadi diantaranya: kurangnya media promosi penjualan, pelanggan sulit mendapatkan informasi stok barang yang tersedia, kurangnya media keamanan untuk bertransaksi, dan pembuatan laporan penjualan masih manual. Untuk mengatasi masalah yang terjadi penulis memberikan solusi dengan sistem e-commerce menggunakan Content Management System (CMS) dengan tools dari Wordpress sebagai solusi pemecahan masalah pada sistem yang sedang berjalan saat ini. Analisis bisnis pada penelitan ini menggunakan metode Business Model Canvas (BMC) dibantu dengan teknik Search Engine Optimization (SEO) dalam penerapannya untuk membantu website tampil di halaman mesin pencari. Hasil dari penerapan e-commerce ini dapat memudahkan pelanggan untuk melakukan pemesanan, meningkatkan kepercayaan pelanggan saat bertransaksi dan pembuatan laporan yang akurat.
\end{abstract}

Kata Kunci: e-commerce, website, content management system, business model canvas, search engine optimization

\begin{abstract}
Queenita Classic is a classic motorcycle spare parts shop that was formed since 2013 which provides various products such as tanks, lamp reflectors, turn signals, shockbakers, speedometers, and many others. Not only selling spare parts, this company also provides services for installing spare parts. This is certainly an added value for Queenita Classic in providing services to customers. In running its business, Queenita Classic always experiences problems that occur, including: lack of sales promotion media, customers find it difficult to get information on available stock items, lack of security media for transactions, and making sales reports is still manual. To overcome the problems that occur, the author provides a solution with an e-commerce system using a Content Management System (CMS) with tools from Wordpress as a solution to problem solving on the system that is currently running. Business analysis in this research uses the Business Model Canvas (BMC) method assisted by Search Engine Optimization (SEO) techniques in its application to help websites appear on search engine pages. The results of the application of e-commerce can make it easier for customers to place orders, increase customer confidence when making transactions and create accurate reports.
\end{abstract}

Keywords : e-commerce, website, content management system, business model canvas, search engine optimization

\section{PENDAhUluAN}

Dalam perkembangan teknologi modern yang serba digital saat ini semua aktivitas kegiatan jual-beli baik produk fisik, produk digital, maupun jasa dapat dilakukan secara cepat, murah, dan mudah tanpa adanya batasan waktu dan ruang. Hal ini dimanfaatkan bagi pembisnis untuk mengembangkan usahanya secara online, salah satu pemanfaatan bisnis online saat ini dikenal dengan sebutan $e$-commerce. Pengertian $e$-commerce adalah pembelian, penjualan, dan pemasaran barang serta jasa melalui sistem elektronik. E-commerce sendiri merupakan bagian dari $e$-business dimana e-business itu mencakup seluruh kegiatan bisnis seperti pembelian, pembayaran, manajemen rantai persediaan, pelayanan kepada pelanggan atau masyarakat, dan hubungan kepada mitra bisnis [1].

Queenita Classic merupakan suatu usaha jenis wirausaha kecil dan menengah yang bergerak di bidang otomotif yang menyediakan berbagai produk sparepart motor klasik baik itu sparepart variasi ataupun custom, seperti tangki, reflektor lampu, lampu sein, shockbaker, spedometer, dan masih banyak yang lainnya. Saat ini, Queenita Classic hanya membuka toko fisik untuk melayani pelanggan dan dibantu media promosi melalui Instagram. pelanggan yang datang hanyalah pelanggan yang sedang berada di sekitar toko, karena toko terletak di pinggir jalan raya. Namun, dengan sistem yang berjalan saat ini masih terdapat beberapa permasalahan yang terjadi seperti, kekurangan dalam penyimpanan data, serta pencetakan laporan masih berupa pencatatan dalam bentuk arsip, ketersediaan stok tidak dicatat, sehingga sulit untuk diketahui pelanggan, dan media promosi untuk mengembangkan usahanya masih kurang, akibatnya penjualan hanya didapat dari pengunjung di sekitar toko dan followers Instagram.

Menurut latar belakang pembahasan diatas penulis ingin membuat sebuah website promosi sekaligus $e$ commerce, melihat usaha penjualan Queenita Classic belum dikenal banyak masyarakat maka penulis ingin mengangkat judul "Penerapan dan Pengembangan Sistem E-Commerce menggunakan CMS Wordpress untuk meningkatkan penjualan pada Queenita Classic". Alasan penulis memilih membuat website karena menurut penulis saat ini website adalah wadah atau media yang tepat untuk mempromosikan produk dan jasa suatu perusahaan di era sekarang ini yang kebanyakan sudah menggunakan website sebagai media penyampaian informasi, sehingga 
diharapkan dengan menggunakan website sebagai media promosi masyarakat dapat mengetahui tentang Queenita Classic. Beberapa studi literatur terkait dengan penelitian yang dilakukan, antara lain: penelitian pertama [2] yang membahas Perancangan Website sebagai media Promosi dan Informasi, penelitian tersebut menggunakan bahasa pemograman PHP dan MySql sebagai database. Penelitian kedua [3] membahas Perancangan Sistem E-Commerce Untuk Memperluas Pasar Produk Oleh-Oleh Khas Pontianak. Metode perancangan sistem E-Commerce menggunakan pendekatan Waterfall dengan pendekatan berorientasi objek. Penelitian ketiga [4] yang membahas tentang Implementasi CMS Wordpress pada Jogja Motor Sports Berbasis E-Commerce, penelitian tersebut menggunakan Rancangan e-commerce dengan metode business model canvas untuk meningkatkan penjualan sparepart pada toko jogja motor sports. Berdasarkan sistem berjalan saat ini dan studi literatur di atas maka peneliti melakukan penelitian untuk membuat model e-commerce sesuai dengan kebutuhan Queenita Classic, perbedaan peneliti lakukan dengan penelitian sebelumnya terletak pada penggunnan conten management system, Di dalam website yang dibuat terdapat fitur retur, dan teknik Search Engine Optimizatuin (SEO) untuk meningkatkan traffic website. Adapun rumusan masalah yang harus dijawab dalam penelitian ini adalah bagaimana model e-commerce dapat meningkatkan penjualan pada Queenita Classic. Manfaat dari penelitian ini adalah membangun hubungan interaksi dalam transaksi penjualan yang dilakukan secara online.

\section{METODE PENELITIAN}

Metode penelitian pada dasarnya merupakan cara ilmiah untuk mendapatkan data dengan tujuan dan kegunaan tertentu.Untuk mencapai tujuan yang diperlukan dibutuhkan metode yang relevan untuk mencapai tujuan yang diinginkan [5]. Yang terlihat pada Gambar 1:

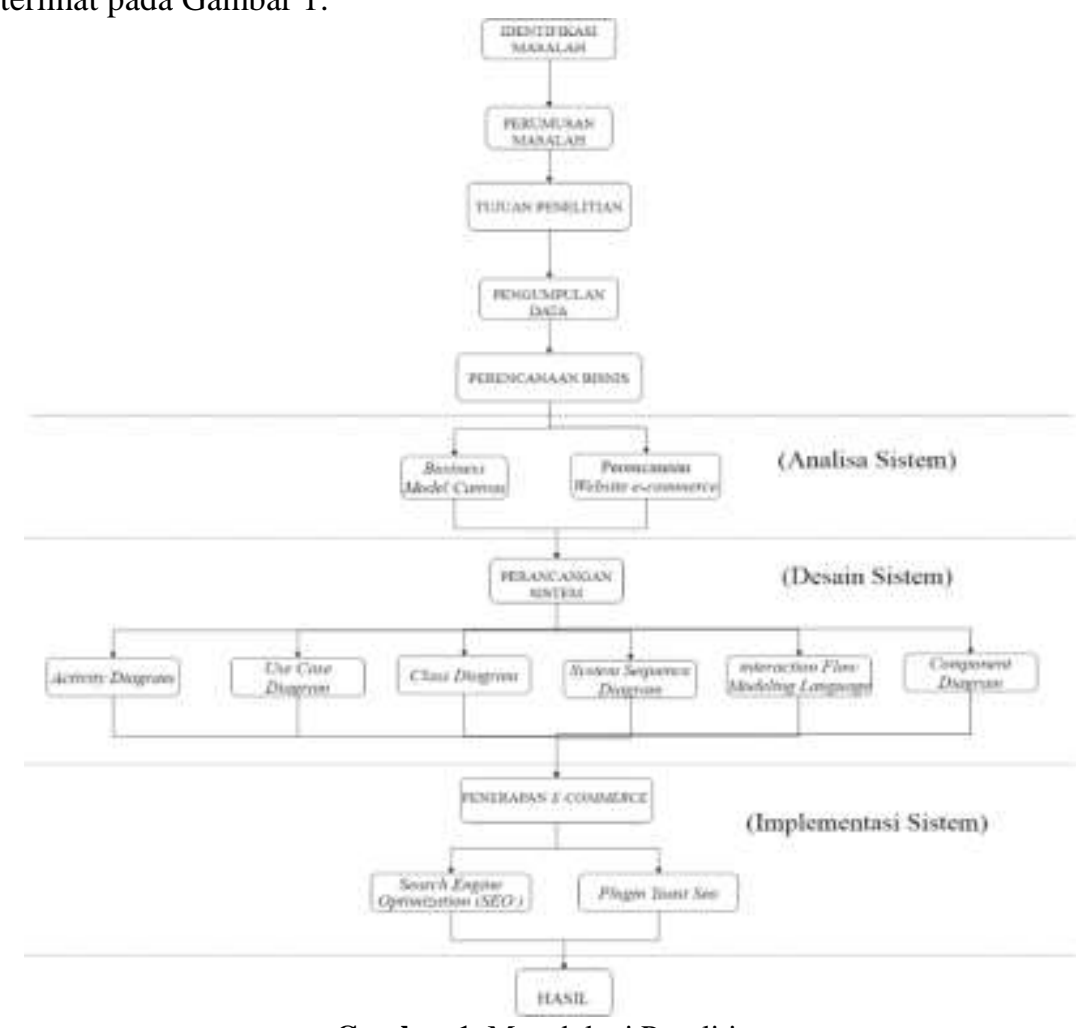

Gambar 1. Metodologi Penelitian

Berdasarkan Gambar 1. penjelasan alur metedolegi penelitian yang dilakukan: tahapan penelitian diawali dengan identifikasi masalah dilakukan dengan wawancara kepada pemilik Queenita Classic, hal ini dilakukan untuk mengetahui kendala dan kebutuhan yang dihadapi Queenita Classic dalam menjalankan usahanya. Tahap kedua adalah perumusan masalah dengan merangkum permasalahan yang terjadi menjadi lebih spesifik, kegiatan yang dilakukan dengan mengamati dan mengeksplorasi permasalahan yang ada pada sistem yang berjalan saat ini, hal ini diperlukan untuk mendefinisikan keinginan dari sistem yang belum tercapai. Tahapan ketiga adalah dengan menentukan tujuan penelitian untuk memperjelas kerangka pemikiran tentang apa saja yang menjadi sasaran dari penelitian ini, agar tidak menyimpang dari tujuan penelitian yang sudah ditentukan.Tahap keempat adalah melakukan pengumpulan data dan informasi untuk lebih memahami sistem yang akan diteliti, pengumpulan data dilakukan 
dengan cara: wawancara, observasi, analisa dokumen, dan studi literatur. Tahapan kelima adalah melakukan perencanaan bisnis pada sistem berjalan dengan membuat business model canvas, hasil yang didapat penulis dapat mengetahui bagaian-bagian apa saja yang menjadi komponen utama dan pendukung dalam proses bisnis berjalan. $B M C$ adalah salah satu alat strategi yang digunakan untuk mendeskripsikan sebuah model bisnis dan menggambarkan dasar pemikiran tentang bagaimana organisasi menciptakan, memberikan, dan menangkap nilai [6]. Langkah selanjutnya dengan melakukan perencanaan sebuah webiste e-commerce sebagai media pemasaran untuk melakukan promosi, teknik yang digunakan dengan tolls Content Management System menggunakan Wordpress. Wordpress adalah sebuah perangkat lunak yang digunakan untuk membuat website. Namun tidak hanya web pribadi dan situs berita, tetapi bisa dijadikan toko online. Wordpress ini sudah sangat popular untuk digunakan sebagai layanan blog [7]. Tahapan keenam adalah melakukan perancangan sistem, hal ini bertujuan agar sistem yang dibangun lebih tepat sesuai dengan kebutuhan dan mengurangi kesalahan pada pembuatan sistem. Adapun pendekatan yang dilakukan adalah dengan UML (Unified Modeling Languege), adapun diagram yang digunakan adalah: Activity Diagram, Use Case Diagram, Class Diagram, System Sequencen Diagram, Interaction Flow Modeling Language, Component Diagram. Tahapan ketujuh adalah penerapan e-commerce dengan melakukan strategi Search Engine Optimization (SEO). SEO merupakan unsur penting pada web untuk memudahkan pencarian pada mesin pencari sehingga dalam penyampaian konten pada web akan menjadi lebih efektif, karena kecenderungan pengguna internet akan memilih web yang berada pada halaman pertama di mesin pencari [8]. Tahapan kedelapan adalah hasil yang telah dilalui serta saran yang berkenaan dengan hasil yang telah dicapai dalam melakukan penelitian.

\section{HASIL DAN PEMBAHASAN}

\subsection{Business Model Canvas}

Berikut ini adalah 9 elemen yang dimiliki Queenita Classic pada Business Model Canvas antara lain:

a. Value proposition adalah nilai yang ditawarkan oleh Queenita Classic kepada pelanggan. Keunggulan produk maupun jasa yang ditawarkan Queenita Classic sebagai pembeda dengan kompetitor lainnya yang bergerak di bidang usaha yang sama. Produk sparepart yang dijual berkualitas dan bergaransi, untuk memudahkan pelanggan Queenita Classic menyediakan jasa pemasangan sparepart di tempat dengan harga yang terjangkau. Dan untuk menarik minat pelanggan terkadang Queenita Classic memberikan harga promo paketan sparepart seperti paketan body motor dengan harga yang murah.

b. Customer Segment, pangsa pasar yang dituju oleh Queenita Classic sangat spesifik karena produk yang dijual merupakan produk atau jasa khusus, yaitu pemilik motor klasik Honda dan Yamaha.

c. Customer Relationship, untuk mendapatkan pelanggan baru dan mempertahankan pelanggan yang sudah ada sangat sulit untuk dilakukan. Hal ini diperlukan strategi untuk menyiapkannya dengan matang. Hal yang dilakukan Queenita Classic seperti:Aktif mengikuti event-event otomotif karena hal ini sangat efektif untuk memperkenalkan Queenita Classic dan produknya kepada pelanggan baru, selain itu untuk memperkenalkan secara luas di media digital Queenita Classic menggunakan media sosial Instagram dan Facebook untuk memasarkan produknya, lalu upayah untuk mempertahankan pelanggan yang sudah ada Queenita Classic melayani konsultasi sebelum pembelian produk agar terhindar dari kesalahan pada saat pembelian dan pemasangan.

d. Channles, untuk mendistribusikan pemasaran Queenita Classic menggunakan media atau sasaran seperti Instagram, WhatsApp, dan Website e-commerce. Hal ini dibutuhkan untuk mengkomunikasikan produk yang ditawarkan kepada pelanggan.

e. Key resources adalah hal-hal yang paling penting yang harus Queenita Classic miliki agar key activities bisa dijalankan dan value proposition bisa diberikan pada pelanggan. Sumber daya yang dimilik Queenita Classic Untuk menunjang keperluan perusahaan seperti, sumber daya manusia terdapat karyawan dan mekanik, lalu ada sumber daya elektronik seperti handphone dan laptop sebagai alat untuk memasarkan produk, dan dari sumber daya peralatan mekanik untuk jasa pemasangan sparepart.

f. Key Activities, semua kegiatan atau aktivitas utama yang dilakukan agar memberikan nilai atau manfaat dapat tecapai aktivitas tersebut diantaranya seperti, melayani pelanggan, penjualan sparepart sebagai produk yang akan dijual dan digunakan untuk pemasangan sparepart, melakukan pemasaran produk agar produk dapat dikenal luas oleh masyarakat dan berminat untuk membeli produk atau jasa yang ditawarkan Queenita Classic.

g. Key Partners, berlangsungnya sebuah usaha ada entitas-entitas yang mendukung usaha tersebut yang dibutuhkan oleh suatu perusahaan. hal ini berguna agar Queenita Classic bisa fokus pada kegiatan utama yang dilakukan, untuk itu Queenita Classic berkerja sama kepada pihak penyedia supplier sparepart untuk menyuplai kebutuhan perusahaan, selain itu Queenita Classic membutuhkan penyedia jasa layanan mengecat karena pekerjaan itu membutuhkan tempat yang luas dan waktu yang cukup lama, jika ada pemesanan melalui Instagram Queenita 
Classic memakai jasa ekspedisi untuk pengiriman produknya, dan Queenita Classic membayar sewa tahunan pihak penyedia jasa domain dan hosting agar website Queenita Classic dapat bekerja dengan baik.

h. Cost structure rincian biaya-biaya yang harus Queenita Classic keluarkan untuk melakukan key activities dan menghasilkan value proposition. Berikut ini pengeluaran yang dikeluarkan Queenita Classic setiap bulannya seperti. Pembayar gaji karyawan dan mekanik, biaya sewa toko, biaya listrik, maintenance alat-alat mekanik, pembayaran jasa domain dan hosting website.

i. Revenue Streams, tentu hal ini yang ingin dicapai oleh suatu perusahaan yaitu dengan menjual produk sebanyakbanyaknya karena hal tersebut akan menjadi pendapatan atau keuntugan yang didapatkan oleh suatu perusahaan, pada Queenita Classic revenue didapat dari penjualan produk sparepart dan penyedia jasa layanan pemasangan sparepart.

Berdasarkan hasil analisis business model canvas, berikut ini merupakan rancangan model bisnis menggunakan Business Model Canvas pada Queenita Classic. Lihat Gambar 2:

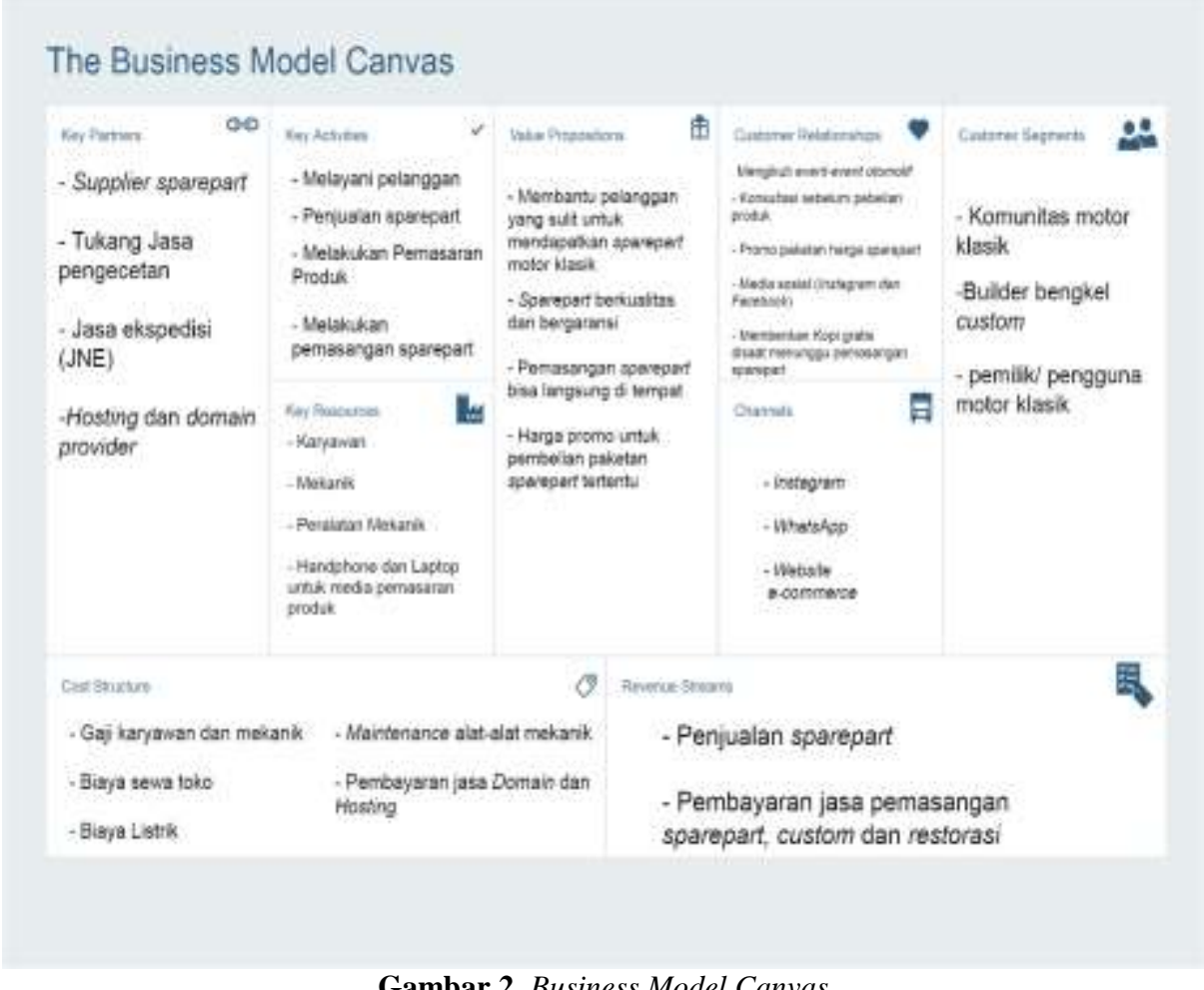

\subsection{Proses Bisnis Usulan}

Diagram activity menggambarkan aliran fungsionalitas dalam sistem. Pada tahap pemodelan bisnis diagram activity dapat digunakan untuk menunjukkan business workflow [9].

a. Activity Diagram Proses Pemesanan Produk

Pada Gambar 3, menjelaskan tentang pelanggan mengunjungi halaman website Queenita Classic lalu pelanggan memilih produk yang ingin dipesan di halaman webiste Queenita Classic setelah menemukan produk yang diinginkan pelanggan dapat mengklik gambar produk di halaman website atau bisa juga masuk ke menu shop. Lalu website akan menampilkan halaman detail produk. Pada halaman detail produk terdapat detail gambar, nama produk, harga produk, deskripsi produk, pilihan warna dan jumlah yang ingin dipesan. Jika sudah, pelanggan dapat menekan tombol add to cart. Lalu akan muncul sidebar cart panel (keranjang belanja) berupa produk yang dipesan.Pelanggan dapat menambah produk lain dengan memilih kembali produk yang akan dipesan. Setelah produk yang dipilih sudah didapat selanjutnya pelanggan menekan tombol checkout, di halaman checkout terdapat detail pemesanan yang telah dibuat, setelah dirasa pemesanan sudah sesuai selanjutnya pelanggan klik tombol proceed to checkout. Jika pelanggan belum terdaftar pada website Queenita Classic maka pelanggan tidak bisa melanjutkan pesanan dan sistem website menampilkan pesan bahwa pelanggan harus melakukan registrasi terlebih dahulu lalu akan di arahkan ke halaman registrasi, setelah itu mengisi form registrasi yang berisi email dan password. Jika sudah melakukan login, pelanggan akan diarahkan ke halaman checkout. Pada halaman checkout pelanggan dapat melihat detail pesanan. Untuk melihat 
Available online at http://jom.fti.budiluhur.ac.id/index.php/IDEALIS/index

jumlah yang harus dibayar pelanggan harus mengisi nama lengkap, telepon, e-mail, alamat, provinsi, kota, kode pos (opsional) dan catatan (opsional) pada form billing details. Setelah itu, sistem website akan menampilkan pilihan jenis layanan pengiriman. Saat ini pelanggan hanya dapat memilih kurir JNE dengan layanan regular atau kilat. Metode pembayaran yang dapat digunakan pelanggan hanya bank transfer. Setelah itu sistem website akan menampilkan total pembayaran dan pelanggan dapat menekan tombol place order. Pelanggan akan diarahkan ke halaman yang menampilkan pesanan berhasil dibuat dan sistem akan mengirimkan notifikasi pesanan berhasil dibuat.

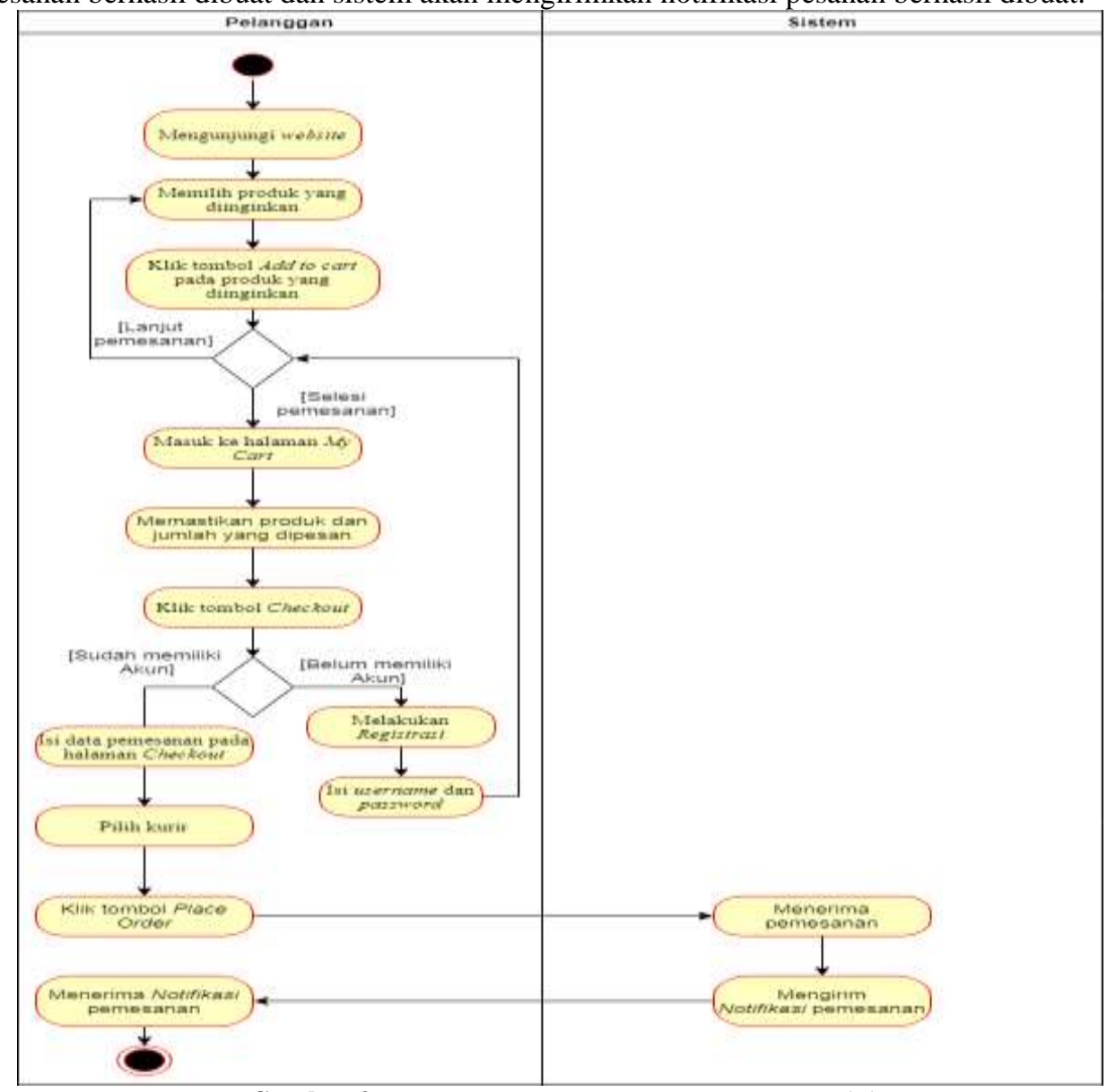

Gambar 3. Activity Diagram Proses Pemesanan Produk

b. Activity Diagram Proses Pembayaran

Pada Gambar 4, menjelaskan pembayaran dilakukan oleh pelanggan dengan mentransfer uang ke rekening Queenita Classic, selanjutnya pelanggan masuk kembali ke website dan ke menu confirm payment. Selanjutnya pelanggan diwajibkan mengisi form nama, phone, order, total transfer, pilih bank yang ditransfer, dan wajib foto slip bukti transfer. Setelah form terisi semua klik submit. Setelah itu sistem website akan mengirimkan notifikasi kepada pelanggan proses pembayaran berhasil dan status pemesanan menjadi proses. 
Available online at http://jom.fti.budiluhur.ac.id/index.php/IDEALIS/index

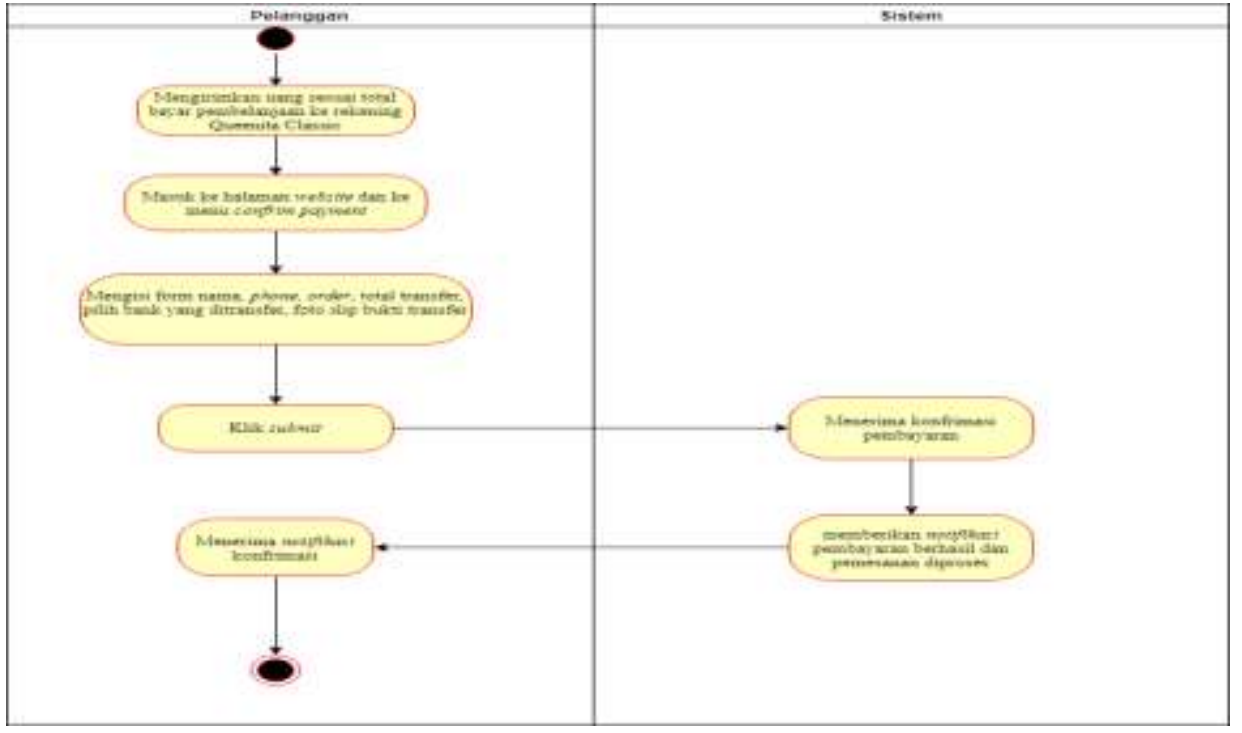

Gambar 4. Activity Diagram Proses Pembayaran

\subsection{Use Case Diagram}

Diagram yang menggambarkan interaksi antara aktor dengan sistem yang digambarkan secara berurutan sesuai alur sistem yang akan berjalan. sebuah Use case berisi apa yang dilakukan oleh sistem atau apa yang terjadi pada sistem [10].

\section{a. Use Case Diagram Master}

Pada Gambar 5, menggambarkan apa yang akan dikerjakan oleh user pada Queenita Classic yang terdiri dari Actor Admin akan melakukan add new product, edit product, delete product, add new categories, edit categories, dan delete categories. Actor pelanggan dapat melakukan proses input order, confrim payment, order tracking, retur, sedangkan Actor admin dapat melakukan proses verifikasi confrim payment, update order status, entry resi pengiriman, proses retur dan untuk proses pembuatan laporan yang terdiri dari use case cetak laporan penjualan, cetak laporan pemesanan, cetak laporan pembayaran, cetak laporan retur, dan cetak laporan produk terlaris yang dilakukan Admin secara berkala, laporan-laporan tersebut dapat juga di akses oleh pemilik.
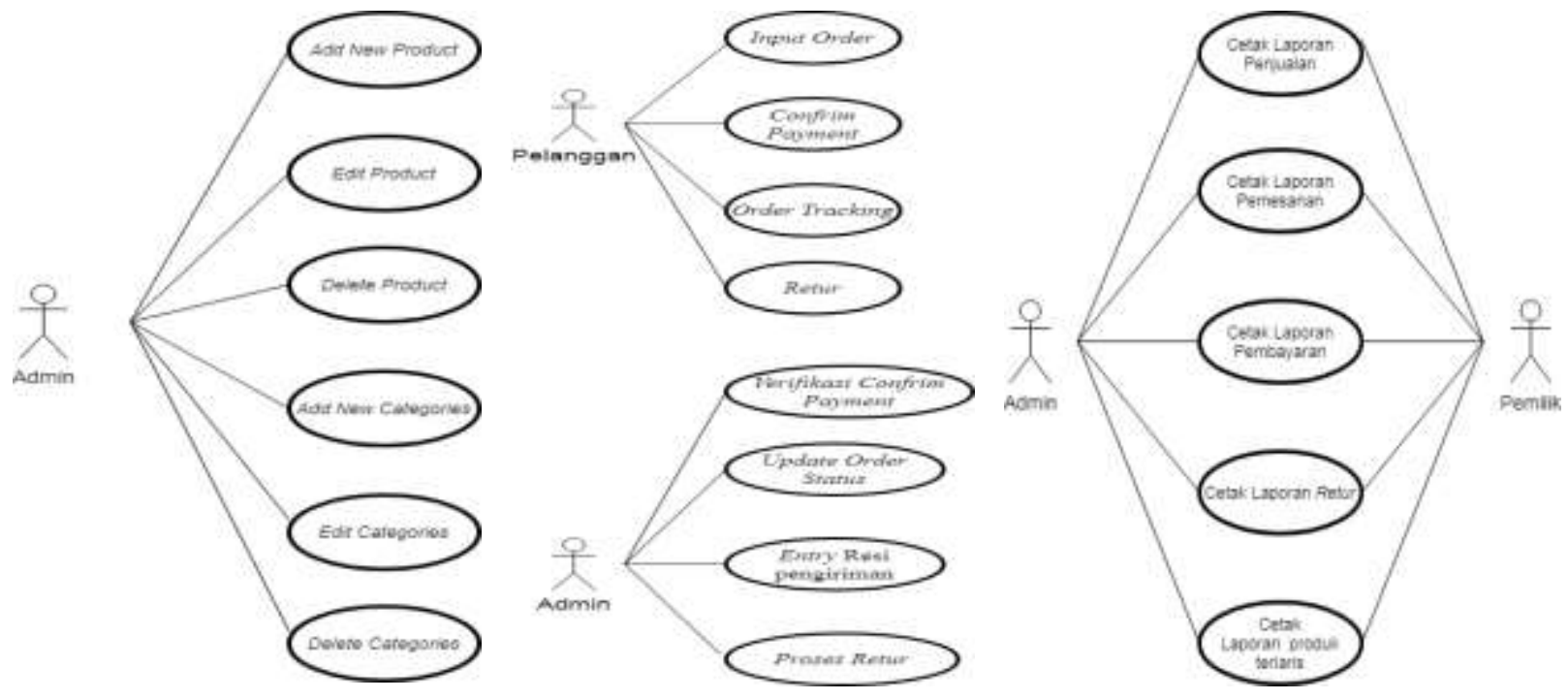

Gambar 5. Use Case Diagram 
Available online at http://jom.fti.budiluhur.ac.id/index.php/IDEALIS/index

\subsection{Rancangan Layar}

Rancangan layar adalah sebuah prototipe desain tampilan awal sebuah website yang berfungsi sebagai antar muka pengguna dengan sistem, atau biasa disebut userinterface.

a. Rancangan Layar Home

Pada Gambar 6 rancangan layar home merupakan tampilan awal ketika pelanggan mengunjungi website queenitaclassic.com, pada halaman ini pelanggan bisa melakukan berbagai aktivitas seperti melihat my account dan produk-produk yang ditawarkan.

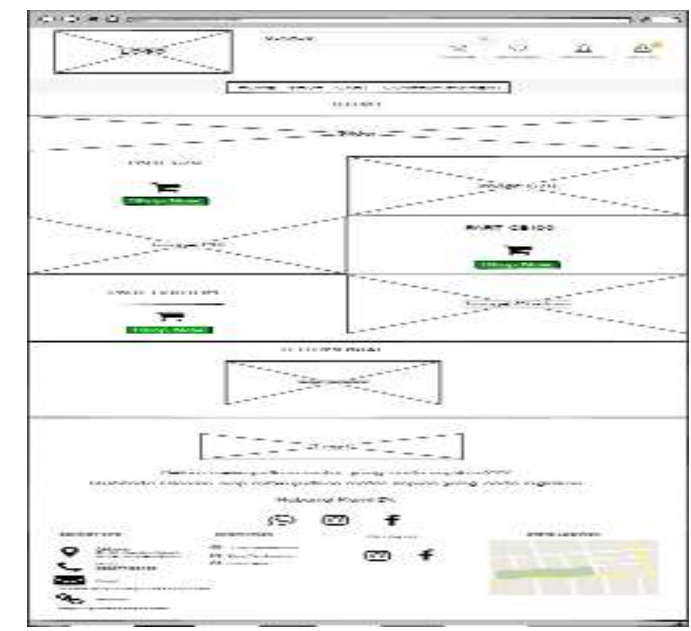

b. Rancangan Layar Checkout

Gambar 6. Rancangan Layar Home

Pada Gambar 7 halaman ini pelanggan harus diwajibkan mengisi form billing details sebelum memilih jasa kurir yang digunakan dan melakukan proses pembayaran pemesanan produk.

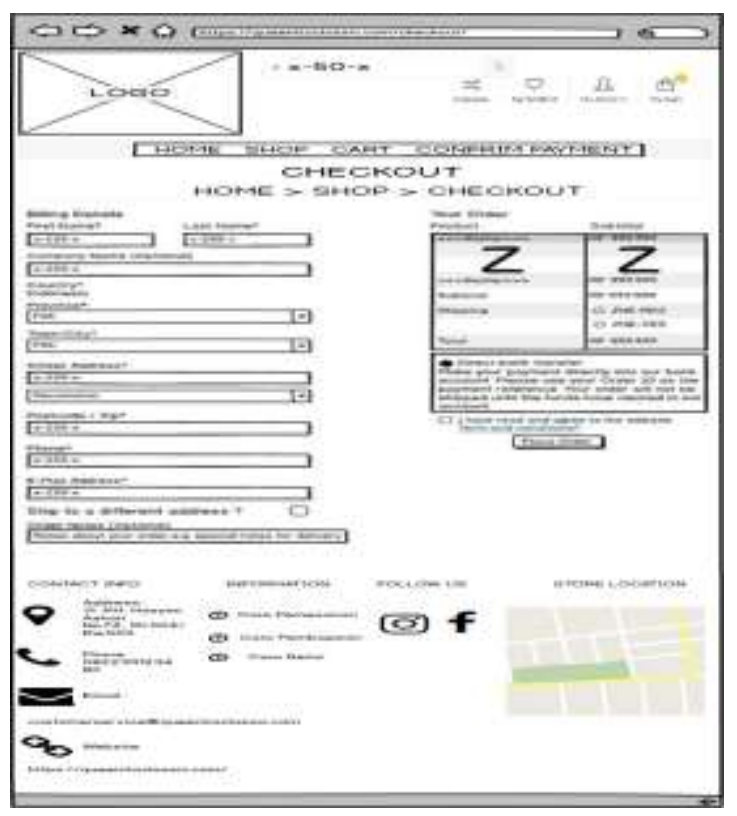

Gambar 7. Rancangan Layar Checkout

c. Rancangan Layar Confrim Payment

Pada gambar 8 halaman ini pelanggan akan melakukan konfrimasi pembayaran setelah melakukan pemesanan produk, pelanggan harus mengisi nama, no order harus sesuai, no. telepon, dan transfer amount harus sesuai dengan jumlah yang harus dibayar, pilih bank transfer dan harus upload bukti slip transfer, selanjutnya klik button submit. 
Available online at http://jom.fti.budiluhur.ac.id/index.php/IDEALIS/index

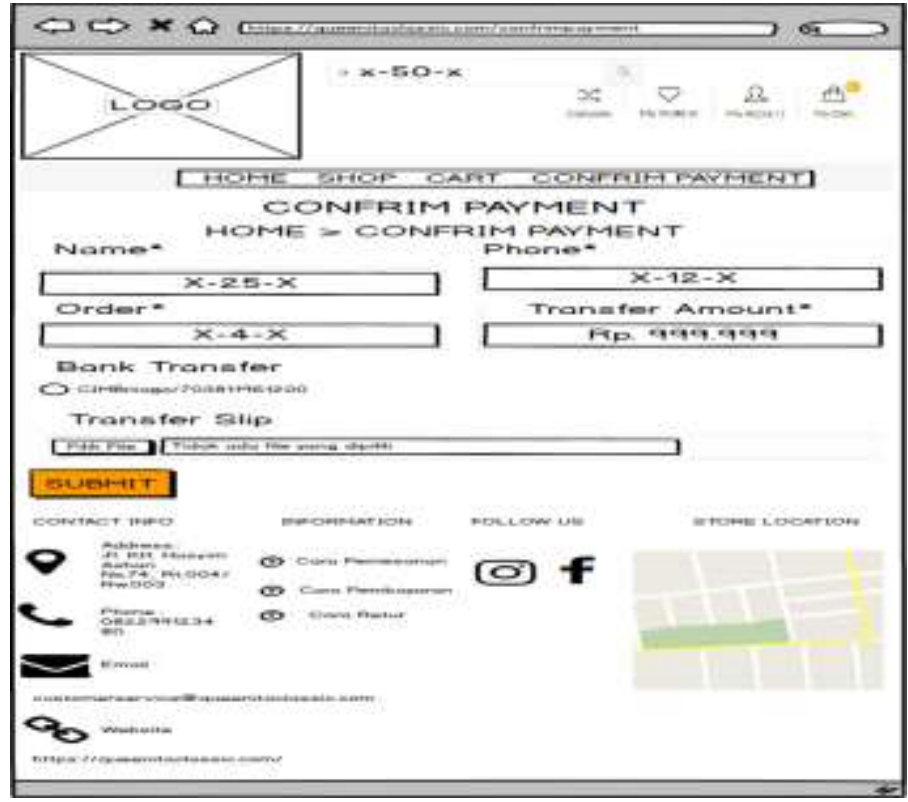

Gambar 8. Rancangan Layar Confirm Payment

d. Rancangan Layar Retur

Pada Gambar 9 adalah rancangan layar retur halaman ini pelanggan dapat melakukan proses permohonan retur dengan mengisi form retur dengan alasan untuk melakukan retur, seteah form terisi selanjutnya klik button submit.

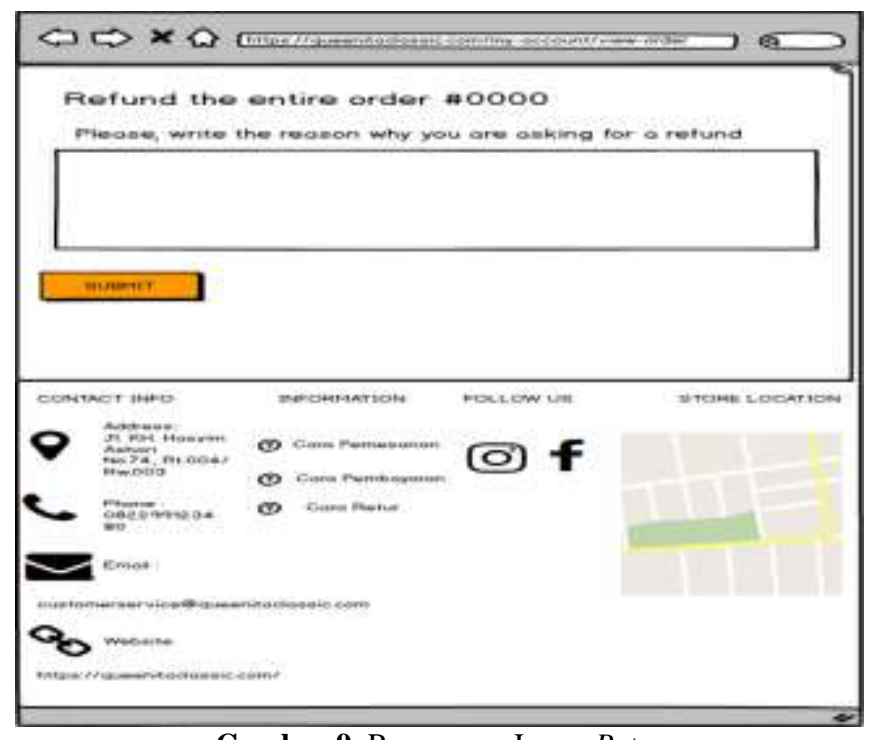

Gambar 9. Rancangan Layar Retur

\subsection{Strategi Search Engine Optimization (SEO)}

Strategi Search Engine Optimization (SEO) adalah strategi yang dilakukan untuk mengoptimasi website yang sudah dibuat akan dapat tampil dihalaman pertama pada mesin pencari, berikut ini adalah langkah-langkah untuk mengoptimasi SEO:

a. Gambar 10 menjelaskan tentang optimasi Yoast SEO dengan melakukan optimasi pada setiap halaman produk website. Yaitu dengan penentuan keyphrase atau kata kunci produk, SEO title. Slug/Permalink, Meta Description, Image Optimization dan konten. Pastikan untuk kolom SEO Title dan Meta description berwarna hijau, agar pada mesin pencari dapat menemukan halaman produk yang sudah kita optimasi. 
INDONESIA JOURNAL INFORMATION SYSTEM (IDEALIS)

Volume 4, Nomor 1, Januari 2021

ISSN 2684-7280 (online)

Halaman 107-116

Available online at http://jom.fti.budiluhur.ac.id/index.php/IDEALIS/index

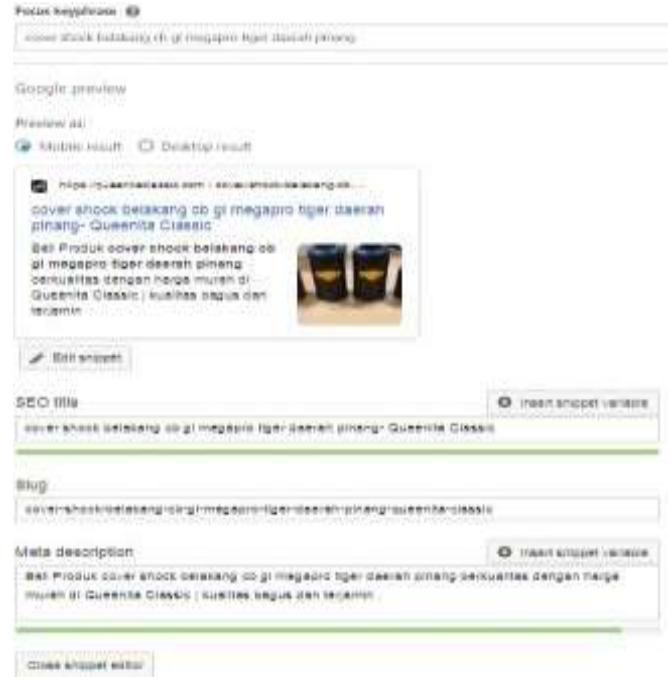

Gambar 10. Optimasi SEO Halaman Produk

b. Pada Gambar 11 adalah menambahkan alt text pada gambar produk.

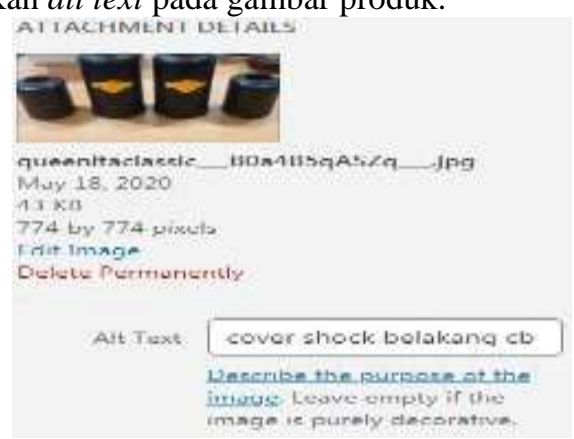

Gambar 11. Optimasi SEO Pada Gambar Produk

c. Gambar 12 adalah hasil dari implementasi $S E O$, berikut ini adalah hasil dari penerapan strategi $S E O$ yang sudah diimplementasikan pada penelitian ini, hasil SEO dilakukan pada 28 Juni 2020, pada jam 12.49 WIB.

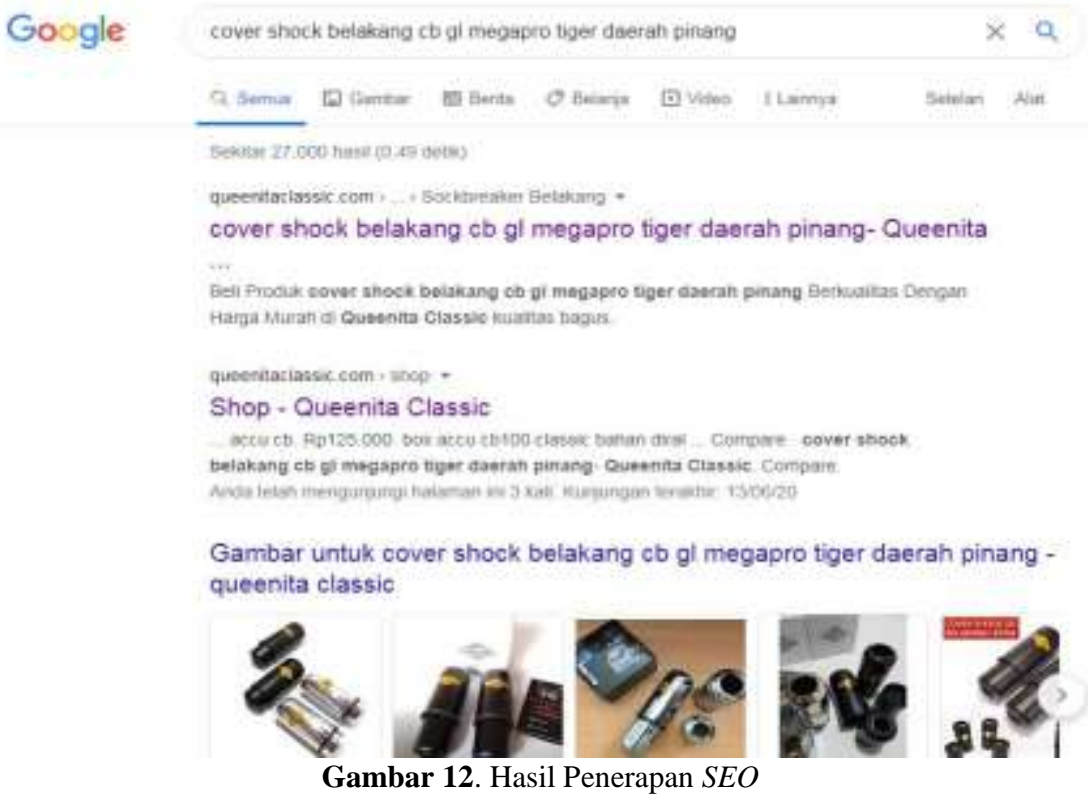




\section{KESIMPULAN}

Kesimpulan dari hasil analisis dan implementasi E-Commerce menggunakan CMS Wordpress pada Queenita Classic yaitu dengan adanya sistem website e-commerce dapat memudahkan Queenita Classic melakukan promosi penjualan sehingga jangkauan pasar menjadi luas, di dalam website juga terdapat fitur informasi stok produk dan fitur order yang berfungsi untuk meningkatkan kepercayaan pelanggan dan mengetahui informasi status pemesanan, sistem ini juga membantu Queenita Classic dalam pembuatan laporan dengan capat dan akurat hal ini dikarenakan pada sistem website Queenita Classic terdapat fitur cetak laporan yang akan otomatis membuat laporan sesuai periode yang diinginkan, serta penjualan akan lebih maksimal dengan menggunakan teknik SEO On-Page yang berfungsi agar website berada di halaman pertama mesin pencari dan teknik pemasaran digital seperti Instagram dan Facebook yang akan back link ke website utama.

\section{DAFTAR PUSTAKA}

[1] E. S. Asih, and K. Kasmi, "E-Commerce Web Mobile untuk layanan Jual Beli HP yang Berbasis Teknologi," Konferensi Mahasiswa Sistem Informasi, vol. 6, no. 1, pp. 83-89, 2018.

[2] P. S. Hasugian, "Perancangan Website sebagai Media Promosi dan Informasi," Journal of Informatic Pelita Nusantara, vol. 3, no. 1, pp. 82-86, 2018.

[3] S. Kosasi, "Perancangan Sistem E-Commerce Untuk Memperluas Pasar Produk Oleh-Oleh Khas Pontianak," Snastia, Oktober, pp. 110-119, 2015.

[4] B. A. Sutrisno, and B. C. Putra, "Implementasi CMS Wordpress Pada Jogja Motor Sports Berbasis E-Commerce," IDEALIS, vol. 3, no. 1, pp. 2-7, 2020.

[5] Sugiyono, "Metode Penelitian Kuantitatif Kualitataif dan Kombinasi (Mixed Methods)," Edisi 1, Bandung: Alfabeta, 2016.

[6] M. F. Gunawan, "Perancangan Business Model Canvas sebagai Alternatif Strategi Bisnis Budidaya Ikan Gurame (Studi Kasus pada UKM Mitra Mina. Desa Sridadi, Kecamatan Kalirejo, Lampung Tengah),” Skripsi, FISIP Unila, 2016.

[7] R. Rachmawati, “Teknik dan Ideologi Penerjemahan Di Wordpress," Madah, vol. 7, no. 2 pp. 211-224, 2016.

[8] A. Q. A., and J. D. Pribadi, "Pembuatan Website Menggunakan CMS Wordpress," Jurnal Aplikasi Bisnis, vol. 3, no. 1, pp. 287-292, 2017.

[9] A. Azis, N. Fuat, and K. Yahya, “Aplikasi Jadwal Event Cb Sejawa Timur Berbasis Android,” J-TIIES, vol. 1, no. 1, pp. 471-478, 2017.

[10] T. Loveri, "Sistem Informasi Aplikasi Pengelolaan Transaksi Keuangan dan Pendataan Konsumen pada CV. Puplas," Jurnal Sains dan Informatika, vol. 4, no. 2, pp. 138-149, 2018. 